La orfebrería en los Andes en la época inca (siglos XV$\mathrm{XVI})$

\title{
Los tupus y estatuillas de plata inka: una aproximación a sus aleaciones
}

Une approche de l'étude des alliages d'argent des tupus et des figurines incas Approach to Inka tupus and figurines silver alloys

\section{Luisa Vetter Parodi y Maria Filomena Guerra}

\section{(2penEdition} Journals

Edición electrónica

URL: http://journals.openedition.org/bifea/8397

DOI: 10.4000/bifea.8397

ISSN: 2076-5827

Editor

Institut Français d'Études Andines

Edición impresa

Fecha de publicación: 1 abril 2017

Paginación: 171-192

ISSN: 0303-7495

\section{Referencia electrónica}

Luisa Vetter Parodi y Maria Filomena Guerra, « Los tupus y estatuillas de plata inka: una aproximación a sus aleaciones », Bulletin de l'Institut français d'études andines [En línea], 46 (1) | 2017, Publicado el 08 abril 2017, consultado el 05 noviembre 2020. URL : http://journals.openedition.org/bifea/8397 ; DOI : https://doi.org/10.4000/bifea.8397

Les contenus du Bulletin de l'Institut français d'études andines sont mis à disposition selon les termes de la licence Creative Commons Attribution - Pas d'Utilisation Commerciale - Pas de Modification 4.0 International. 


\title{
Los tupus y estatuillas de plata inka: una aproximación a sus aleaciones
}

\author{
Luisa Vetter Parodi* \\ Maria Filomena Guerra**
}

\begin{abstract}
Resumen
El tupu, tupo o prendedor es un objeto que ha sido, y sigue siendo, parte de la vestimenta femenina en los Andes desde hace más de 1700 años. No fue usado solamente en vida, ya que hay evidencias arqueológicas de su uso en las capacochas o como ofrenda a las huacas, entre otros. Ha sido elaborado en distintos metales y aleaciones, según la jerarquía de la portadora y la época de uso, desde oro, plata y tumbaga, hasta el cobre, bronce y latón.

Fuera de contexto arqueológico es difícil atribuirle una cronología. En este trabajo hemos intentado verificar si a través de las aleaciones de plata utilizadas para su elaboración, es posible determinar criterios para vincular las épocas de producción, en particular para los tupus miniatura de las figuras de plata o capacochas.

Se analizó por fluorescencia de rayos X (FRX) un grupo de tupus de plata pertenecientes al Museo Inka de la Universidad Nacional de San Antonio Abad del Cusco y del Museo de Oro y Armas del Mundo de Lima. Igualmente se incluyeron en estos análisis algunas figuras de plata del Museo de Oro y Armas del Mundo. Los resultados fueron finalmente comparados con los de las monedas acuñadas en Potosí y con los escasos resultados de análisis de tupus y figuras que se encuentran publicados hasta el momento.
\end{abstract}

Palabras clave: $F R X$, plata, tupu, figura miniatura, inca, aleación

\section{Une approche de l'étude des alliages d'argent des tupus et des figurines incas}

\section{Résumé}

Le tupu, tupo ou broche, est un objet qui depuis plus de 1700 ans fait partie du vêtement féminin des Andes. II n'a pas seulement été utilisé au cours de la vie puisque des évidences archéologiques

* Pontificia Universidad Católica del Perú, Academia Nacional de Ciencias. E-mail: luchivetter@ hotmail.com

${ }^{* *}$ CNRS, ArchAm-UMR 8096, Maison Archéologie \& Ethnologie, 21 allée de I'Université, 92023 Nanterre, France. E-mail: maria.guerra@cnrs.fr 
démontrent aussi son usage, entre autres, dans la cérémonie de la capacocha et comme offrande à des huacas. Le tupu a été fabriqué, selon le statut social de celle qui le portait et la mode de l'époque, en divers métaux et alliages comme l'or, l'argent, le tumbaga, le cuivre, le bronze et le laiton.

En dehors de tout contexte archéologique, il est difficile de les dater. Dans ce travail nous avons cherché à établir un rapport entre les caractéristiques des alliages d'argent utilisés et la période de fabrication, en particulier pour les tupus miniatures des figurines capacochas.

Un groupe de tupus en argent appartenant au Museo Inka de I'Universidad Nacional de San Antonio Abad del Cusco et au Museo de Oro y Armas del Mundo de Lima a été analysé par spectrométrie par fluorescence à rayons X (FRX). Quelques figurines capacochas appartenant au Museo de Oro y Armas del Mundo ont également été ajoutées à cette étude analytique. Les résultats obtenus sont comparés avec la composition de monnaies frappées à Potosí ainsi qu'avec les rares tupus et figurines dont les résultats d'analyses ont été publiés.

Mots-clés : $F R X$, argent, tupu, figurine, inca, alliage

\title{
Approach to Inka tupus and figurines silver alloys
}

\begin{abstract}
The tupu, tupo or pin has been manufactured for more than 1700 years to embellish women's clothing in the Andes. Women typically wore clothing pins, but archaeological evidencs shows that these pins were also used as part of the capacocha ceremonies and as an offering to the huacas. Depending on fashion and woman's social status, tupus were made using different metals and alloys such as gold, silver, tumbaga, copper, bronze and brass.

When taken out of context they are difficult to date. In our work we searched for the characteristics of the silver alloys used in their fabrication to check whether any criteria could be linked to their period of production, in particular for the miniature tupus from the capacocha silver figurines.

A group of silver tupus belonging to the Museo Inka of the Universidad Nacional de San Antonio Abad del Cusco, and to the Museo de Oro y Armas del Mundo of Lima were analyzed by X-ray fluorescence (XRF). A few capacocha silver figurines from the Museo de Oro y Armas del Mundo were included in this analytical study. Data obtained were compared to the composition of both silver coins struck in Potosi and the rare published tupus and figurines analysis.
\end{abstract}

Keywords: XRF, silver, tupu, figurine, inca, alloy

\section{INTRODUCCIÓN}

El uso de los objetos netamente nativos, como los tupus, por parte de la población indígena es una tradición que se remonta a tiempos precolombinos. Estos objetos no solo fueron usados en vida, como se observa en diferentes escenas representadas en distintos soportes, como objetos cerámicos, murales, textiles, etc. durante tiempos prehispánicos. También formaron parte de las ofrendas que se ofrecían a los difuntos, huacas, dioses, etc. Es decir, no solo fueron enterrados como parte de la parafernalia suntuaria y «utilitaria» elaborada en metal, sino también fueron ofrecidos a sus dioses o huacas y en cualquier evento importante, como el cierre de los edificios monumentales en uso. Esta parafernalia metálica fue elaborada por un grupo selecto de orfebres que seguían las indicaciones de los sacerdotes para plasmar las formas e iconografía en los objetos de metal (Vetter, 2008; 2013; 2016). 
En el siglo XVI los plateros indígenas no solo se encontraban agrupados en sus comunidades, sino también en los galpones que construyó el virrey Toledo en varias urbes a partir de 1572. Esto permitió que, durante las primeras décadas posteriores a la Conquista, continúen ejerciendo su oficio con instrumentos y tecnologías nativos (Vetter, 2013; 2016). En esta época, la plata fue el metal más empleado para la elaboración de objetos suntuarios y utilitarios, aunque esto no fue siempre así en el caso de la población indígena. Una de las autoras (Vetter) ha realizado un estudio sobre tupus coloniales de la sierra central que se presenta en este mismo número y ha podido determinar que si bien se manufacturaron tupus en plata, también los hay en bronce estañífero - aleación muy utilizada en la época inca-, latón —aleación incorporada por los europeos-y otros bronces que no se encuentran en la bibliografía disponible actualmente.

Muchos ejemplares de tupus de plata son conservados en museos, pero sin contexto arqueológico de procedencia, por lo que no es posible atribuirles a un taller o a un periodo. Entre estos tupus destacan las miniaturas que originalmente habrían pertenecido a las figuras de plata antropomorfas del rito de la capacocha. Solamente algunas figuras conservan hoy sus indumentarias, incluyendo los tupus que prenden sus vestidos, y se podría suponer que los pequeños tupus sueltos pertenecerían a las figuras hoy en día despojadas de su vestimenta.

Sin un mapa de los yacimientos de plata explotados por los incas y sin el conocimiento preciso de las aleaciones que producían, es difícil utilizar estas características geoquímicas y metalúrgicas para obtener datos y conectarlos a la producción incaica. Solamente la plata y sus aleaciones de la época colonial son más conocidas, pues varios autores, buscando la relación entre cambio económico mundial en el siglo XVI y producción de plata en las Américas, realizaron análisis químicos, sobretodo de monedas (por ejemplo Richet et al., 1972; Guerra, 1990; 2000).

Este trabajo pretende verificar si existe una relación entre la composición química de las aleaciones empleadas en la elaboración de los tupus de plata y de las figuras de sacrificio y ofrenda, y también de las monedas de plata acuñadas en los Andes durante el periodo colonial. Siendo muy difícil mover los objetos de su lugar de conservación, o tomar muestras para otros análisis químicos, pues esto afectaría su preservación, su estudio se hizo con un equipo portátil de fluorescencia de rayos X (FRX) sin preparación de la superficie del objeto. Así, serán considerados en este trabajo solamente los elementos mayoritarios de las aleaciones y de este modo, no será posible discutir la cuestión de la proveniencia de la plata.

Para este fin hemos trabajado con la colección del Museo de Oro y Armas del Mundo de Lima (MOAM) y del Museo Inka (MI) de la Universidad Nacional de San Antonio Abad del Cusco (UNSAAC). Las siete piezas de la colección del MOAM no tienen contexto arqueológico de procedencia, mientras que las seis del MI provienen de hallazgos en una región muy cercana a las famosas minas de plata de Potosí (actual Bolivia) que produjeron el metal utilizado en las acuñaciones de la casa de moneda local, así como muchas monedas españolas acuñadas a partir de fines del reinado de Felipe II de España. 


\section{LOS TUPUS Y ESTATUILLAS Y SUS CONTEXTOS}

Los tupus o prendedores son objetos que se utilizaban para prender o sujetar la manta o lliclla que llevaba la mujer sobre sus hombros. También se usaban en pares para sujetar el anaku o vestido a la altura de los hombros (Vetter, 2007; 2009; Vetter \& Carcedo, 2009). Las figuras miniatura de oro, plata y spondylus fueron parte de las capacochas, ofrendadas junto a los 'niños momia' en las altas montañas, en los adoratorios o santuarios de altura. Gran cantidad de las piezas custodiadas en el Museo Inka han sido ubicadas en los Catálogos del Archivo Documentario del museo, lo que ha permitido identificar el contexto arqueológico de donde proceden. Entre estos destacan los objetos del hallazgo hecho en Paucartambo en Cusco (fig. 1), los cuales fueron encontrados en una excavación no autorizada en la zona de Ccorihuayrachina, Chimur, provincia de Paucartambo, en 1947, por Carlos Rodríguez. Esta tumba contenía estatuillas y tupus de metal, así como gran cantidad de madera, arcilla cocida y algunos objetos de piedra azul, concha, restos humanos, pigmentos, lana (sandalias, chuspa) y mimbre. Parte de este material en plata ha sido analizado mediante análisis físico-químicos; los resultados son presentados por Sierra Palomino \& Guerra en este mismo volumen.

A continuación se describe otro contexto conocido:

El lote de objetos comprendidos del presente número [126] al 151 inclusive, fueron hallados en una tumba de Patacancha a 15 Kilómetros de Ollantaitampu [Ollantaytambo en el mapa, figura 1]; con ocasión de las excavaciones practicadas durante la Conmemoración del Cuarto Centenario de la fundación del Cuzco. El conjunto que consiste en la ofrenda funeraria de una tumba estaba depositado en una olla de barro cocido i envuelto en una 'lliclla' (Catálogo Universidad del Cuzco, 1936).

Como parte de este contexto se hallaron estatuillas, tupus, llamas, brazaletes, aquillas $^{1}$ de metal y cuentas de concha. Asimismo, en Sacsaywaman fueron hallados varios tupus de plata, cobre y 'champi'2 (Vetter et al., 2008) en contexto funerario; otros dos proceden de Pachar-Anta y Quillabamba, sin contexto conocido, y uno más no tiene procedencia conocida (ver cuadro 1 y fig. 1).

Cuadro 1 - Información sobre los objetos estudiados del Museo Inka del Cusco en los catálogos del archivo documentario del museo

(*) 126 a 151 es un solo contexto de una tumba de Patacancha; $\left(^{* *}\right)$ se halló asociado con gran cantidad de cerámica, restos óseos humanos y animales

\begin{tabular}{|c|c|c|c|c|c|c|}
\hline Procedencia & $\begin{array}{c}\mathrm{N}^{\circ}{ }^{\circ} \\
\text { Registro }\end{array}$ & Objeto & Material & Sexo & Excavación & Contexto \\
\hline \multicolumn{7}{|l|}{ Walla Walla } \\
\hline & $34 / 1233$ & Ilama & plata & M & $?$ & \\
\hline & $34 / 1234$ & figura & plata & $\mathrm{F}$ & $?$ & \\
\hline & $\begin{array}{c}34 / 1235 \\
(21)\end{array}$ & tupu & plata & & $?$ & \\
\hline
\end{tabular}

1 Vaso de oro o plata.

2 Champi se refiere al bronce en quechua. 
Los tupus y estatuillas de plata inka: una aproximación a sus aleaciones

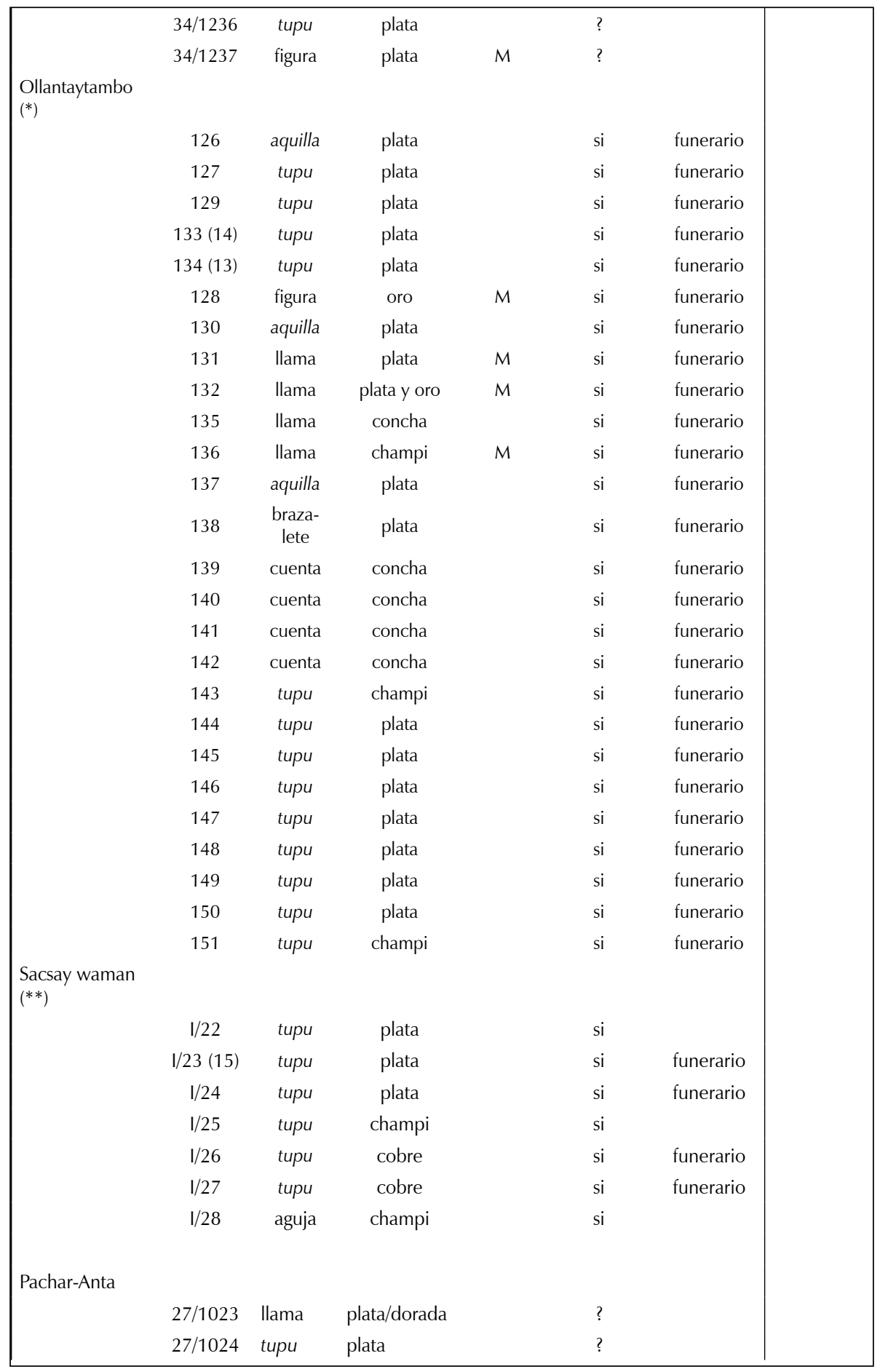




\begin{tabular}{|c|c|c|c|c|}
\hline & $\begin{array}{c}27 / 1025 \\
(19) \\
27 / 1026\end{array}$ & $\begin{array}{l}\text { tupu } \\
\text { tupu }\end{array}$ & $\begin{array}{l}\text { plata } \\
\text { plata }\end{array}$ & $?$ \\
\hline Quillabamba & & & & \\
\hline & $\begin{array}{c}28 / 1272 \\
(18)\end{array}$ & tupu & plata & $?$ \\
\hline & $28 / 1273$ & tupu & champi & ? \\
\hline
\end{tabular}

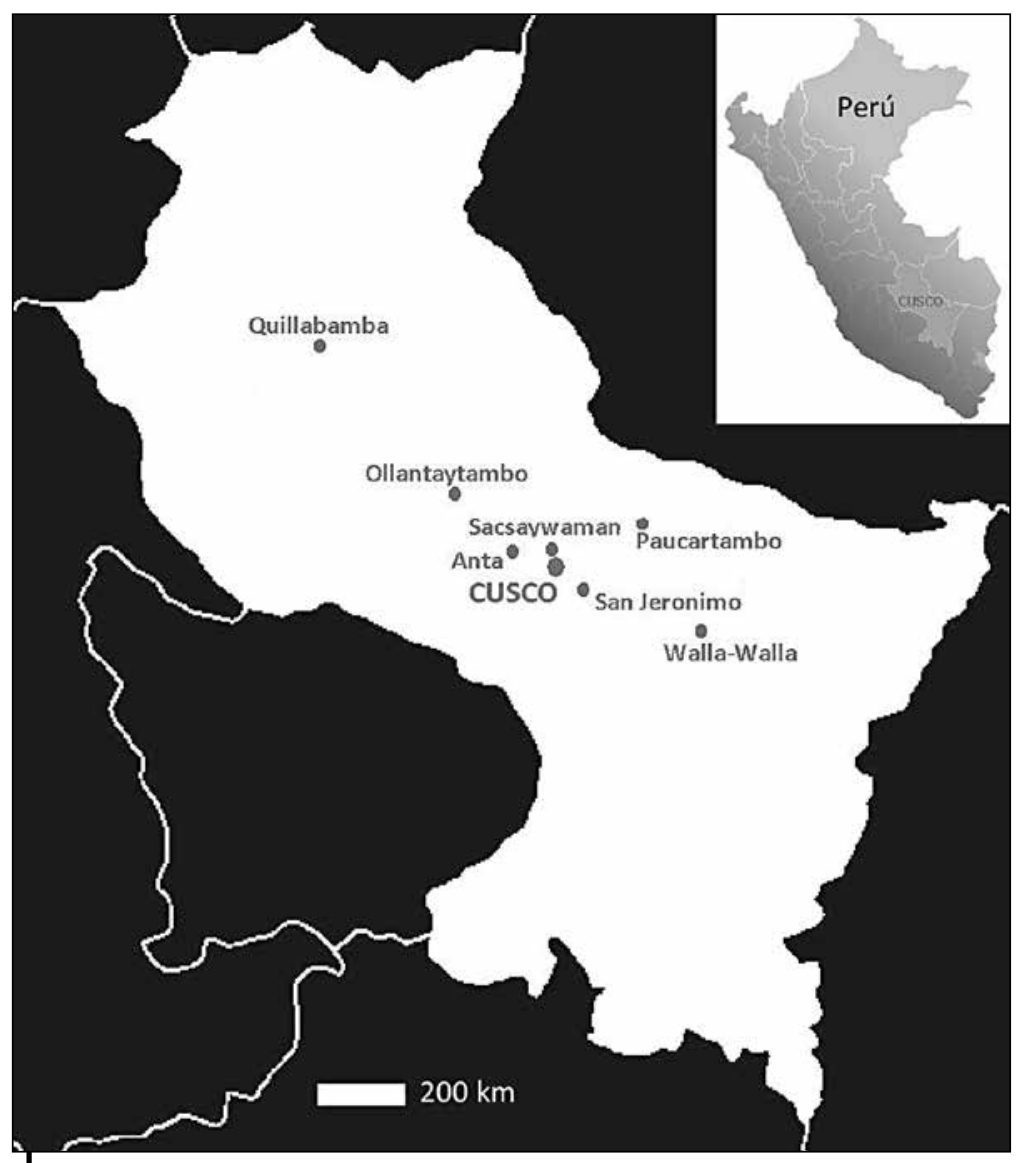

Figura 1 - Ubicación geográfica de los sitios de procedencia de los objetos estudiados

(C) Maria Filomena Guerra (elaborado a partir del mapa del Perú de Wikipedia Commons)

Las piezas del MOAM que hemos analizado no tienen contexto conocido, como ya se mencionó líneas arriba, por lo que nos hemos basado en la tecnología e iconografía para tratar de definir el periodo al cual pertenecen. 


\section{LOS ANÁLISIS NO DESTRUCTIVOS}

Los tupus de plata provenientes de las colecciones del MOAM y del MI fueron estudiados in situ con equipos portátiles y por técnicas no destructivas. Los análisis químicos se realizaron por fluorescencia de rayos X (FRX). A pesar de no necesitar de una preparación previa de la superficie del objeto - lo que es un requisito fundamental en nuestro caso-, este método proporciona resultados únicamente para la superficie de la pieza (Guerra, 2008; Troalen \& Guerra, 2016). Antes de efectuar el análisis químico de sus aleaciones, todos los tupus fueron observados por microscopia óptica con fotografía digital para determinar la región de análisis y apreciar la técnica del platero.

La composición química de los tupus del MOAM fue determinada con un analizador Thermo Scientific Niton modelo XL3T 950 GOLDD para metales preciosos, propiedad de Symtek - Perú. En el MI se utilizó el equipo que pertenece a la Universidad Nacional de San Antonio Abad del Cusco, un analizador Olympus Innov-X DELTA modelo Professional para metales preciosos. En las figuras 2 y 3 se muestra uno de los tupus en el stand del analizador y la imagen dada por la cámara donde se encuentra, indicando la región de análisis.

Para poder comparar los resultados obtenidos para las dos colecciones, se utilizó un conjunto de patrones de plata de Goodfellow y de CLAL (Comptoir LyonAlemand, Louyot et $\mathrm{Cie}$ ) conteniendo concentraciones variables de cobre que fueron evaluadas con los dos analizadores. A partir del patrón de plata Stirling de Goodfellow (92,5\% de plata y 2,5\% de cobre), utilizado como material de ensayo, se calcularon las composiciones de los otros patrones para verificar la precisión y exactitud de los resultados. Las concentraciones obtenidas se encuentran en el cuadro 2. Se observa la buena concordancia entre los valores certificados y los valores medidos.
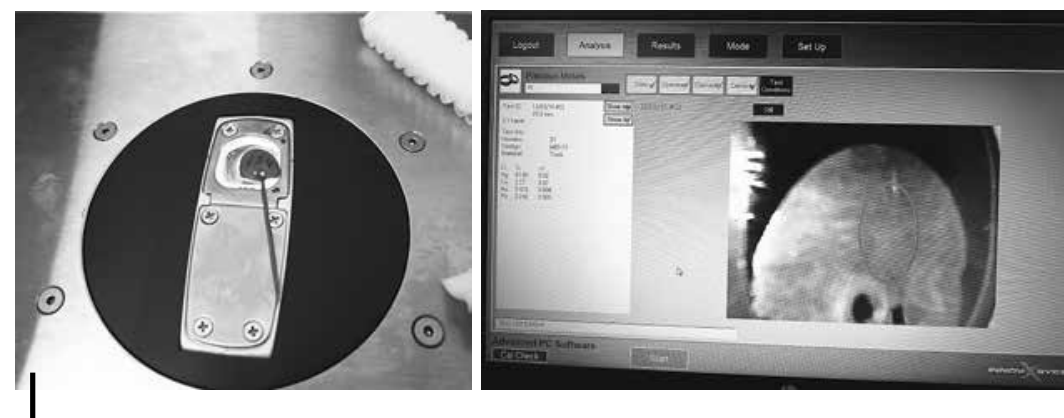

Figuras 2 y 3 - Análisis de uno de los tupos de plata posicionado en el stand del analizador (izquierda). Se puede elegir la región de análisis a través de la imagen dada por la cámara del analizador (derecha).

(c) L. Vetter \& M. F. Guerra 
Cuadro 2 - Composición (C - valor certificado; $\mathrm{M}$ - valor medido) del conjunto de patrones de Goodfellow y de CLAL analizados con los dos analizadores para poder relacionar los resultados obtenidos en ambos museos.

\begin{tabular}{|c|c|c|c|c|}
\hline & & $\mathrm{Ag} \%$ & $\mathrm{Cu} \%$ & $\mathrm{Au} \%$ \\
\hline \multirow[t]{2}{*}{ Goodfellow 1} & C & 85 & 15 & \\
\hline & $M$ & 85,2 & 14,8 & \\
\hline \multirow[t]{2}{*}{ Goodfellow 2} & C & 80 & 20 & \\
\hline & M & 80,1 & 19,9 & \\
\hline \multirow[t]{2}{*}{ Goodfellow 3} & C & 71 & 29 & \\
\hline & $M$ & 70,1 & 29,9 & \\
\hline \multirow[t]{2}{*}{ CLAL 1} & C & 90 & 5 & 5 \\
\hline & M & 90,0 & 5,1 & 4,9 \\
\hline \multirow[t]{2}{*}{ CLAL 2} & C & 73 & 28 & \\
\hline & M & 72,5 & 27,5 & \\
\hline \multirow[t]{2}{*}{ CLAL 3} & C & 93 & 7 & \\
\hline & $M$ & 92,6 & 7,4 & \\
\hline
\end{tabular}

\section{LAS ALEACIONES DE LOS TUPUS Y DE LAS ESTATUILLAS}

Los resultados obtenidos por FRX para los tupus de plata del MI y del MOAM (figs. 4-11), normalizados al 100\%, se encuentran en el cuadro 3. En él se presentan las medias de las concentraciones obtenidas para dos o tres puntos de análisis de cada objeto. Además de los dos elementos mayoritarios (plata y cobre), se han agregado en el cuadro las concentraciones encontradas de oro, de plomo y de estaño. Los valores obtenidos se encuentran con frecuencia próximos a los límites de detección (cerca de $0,1 \%$ ), por lo que no serán comparados con los valores publicados para objetos y monedas.

Además de los tupus, se analizaron por FRX, cinco figuras capacocha de plata cuyos resultados fueron incluidos en el cuadro 3. Las estatuillas (una femenina vaciada, dos masculinas vaciadas y dos llamas, una vaciada y la otra laminada) pertenecen al MOAM y se pueden apreciar en las figuras 12-16. Las dos llamas son de tipos muy diferentes, la llama laminada parece de tipo más tradicional, y podría haber sido elaborada en un periodo distinto.

En la figura 17 se comparan las concentraciones de plata y cobre de las estatuillas y tupus analizados. Se adjuntó al gráfico los escasos tupus y estatuillas de la región de Cusco y otras cercanas, cuya composición es conocida. Además de los objetos del hallazgo de Paucartambo perteneciente al Museo Inka, publicados en este mismo número por Sierra Palomino \& Guerra, añadimos al gráfico varias figuras capacocha de plata de iconografía tradicional. Se tratan de las cuatro figuras provenientes de la isla Coati (Isla de la Luna, lago Titicaca, actual Bolivia), pertenecientes a la colección del Museo de Etnografía de Berlín, publicadas por Guerra et al. en este mismo número y la figura antropomorfa femenina de la 


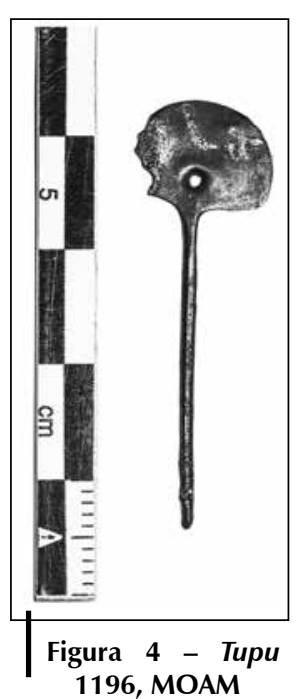

(C) L. Vetter \& M. F. Guerra

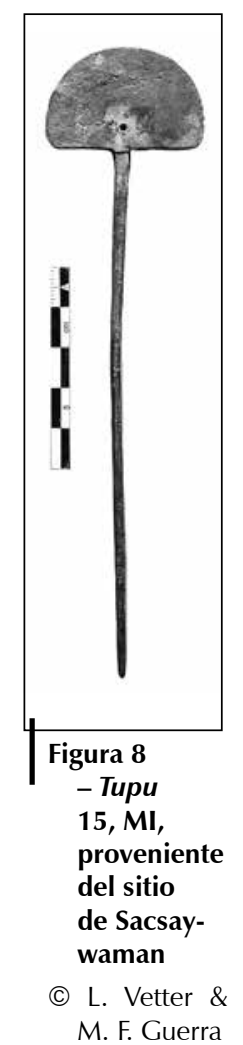

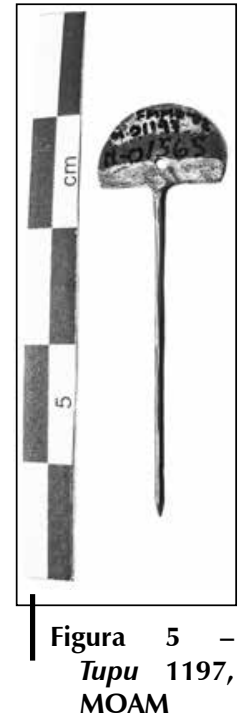

(C) L. Vetter \& M. F. Guerra

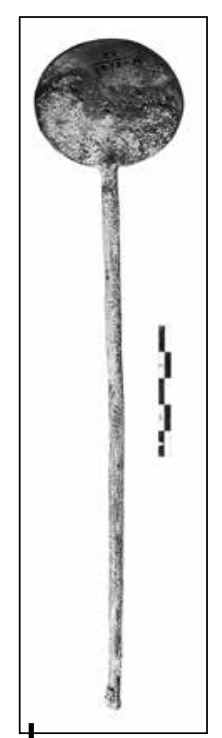

Figura 9 Tupu 18, MI, proveniente del sitio de Quillabamba

(C) L. Vetter \& M. F. Guerra

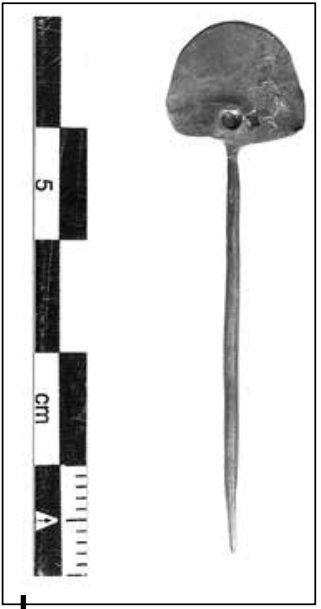

Figura 6 - Tupu 13, MI, proveniente del sitio de Ollantaytambo (Patacancha)

(C) L. Vetter \& M. F. Guerra

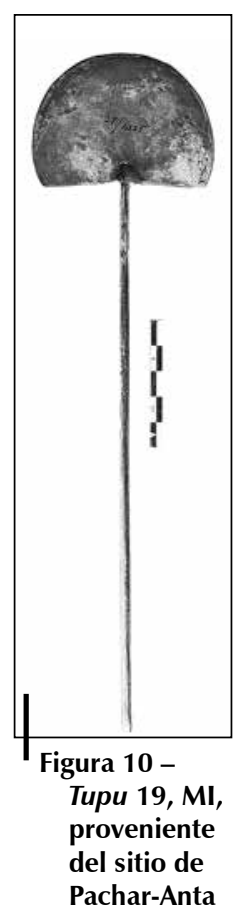

(C) L. Vetter \& M. F. Guerra

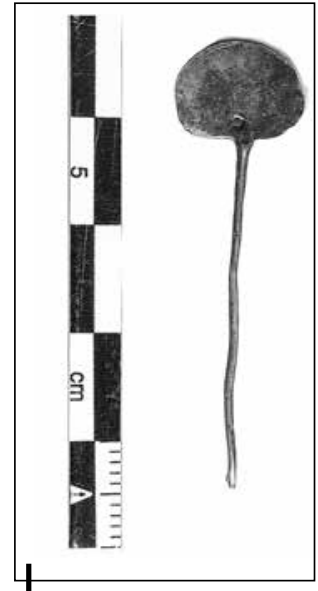

Figura 7 - Tupu 14, MI, proveniente del sitio de Ollantaytambo (Patacancha)

(C) L. Vetter \& M. F. Guerra

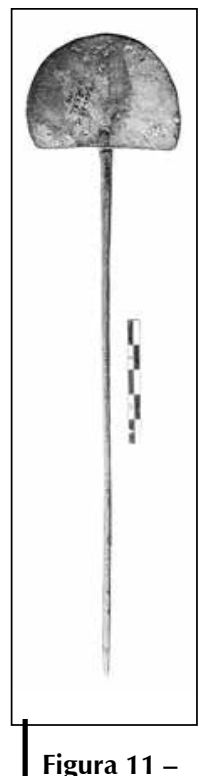

Tupu 21, MI, proveniente del sitio de Walla Walla

(C) L. Vetter \& M. F. Guerra 
Cuadro 3 - Resultados obtenidos por FRX, normalizados al $100 \%$, para los tupus de plata del MOAM y del MI y para cinco estatuillas de plata del MOAM

\begin{tabular}{|c|c|c|c|c|c|c|}
\hline Tipo de objeto & Referencia & Ag \% & $\mathrm{Cu} \%$ & $\mathrm{Au} \%$ & $\mathrm{~Pb} \%$ & Sn \% \\
\hline \multirow[t]{8}{*}{ Tupu } & MO - 1196 & 88,1 & 11,6 & 0,2 & 0,1 & 0,1 \\
\hline & MO - 1197 & 93,8 & 5,9 & 0,3 & $<0,1$ & $<0,1$ \\
\hline & MI - 13 & 97,3 & 2,1 & 0,4 & 0,2 & $<0,1$ \\
\hline & MI - 14 & 93,5 & 5,8 & 0,6 & 0,1 & $<0,1$ \\
\hline & MI - 15 & 95,8 & 3,6 & 0,1 & 0,5 & $<0,1$ \\
\hline & MI - 18 & 94,5 & 5,1 & $<0,1$ & 0,4 & $<0,1$ \\
\hline & MI - 19 & 94,7 & 4,4 & 0,2 & 0,2 & 0,5 \\
\hline & MI - 21 & 95,5 & 4,1 & 0,1 & 0,3 & $<0,1$ \\
\hline \multirow[t]{6}{*}{ Estatuillas } & $\mathrm{MO}-1175$ & 97,2 & 2,1 & 0,5 & 0,2 & $<0,1$ \\
\hline & MO - 1159 & 90,1 & 9,7 & 0,1 & 0,1 & $<0,1$ \\
\hline & MO - 1158 & 98,2 & 1,3 & 0,5 & $<0,1$ & $<0,1$ \\
\hline & MO - 1158 & 98,7 & 1,3 & $<0,1$ & $<0,1$ & $<0,1$ \\
\hline & $\mathrm{MO}-1179$ & 87,7 & 12 & 0,2 & 0,2 & $<0,1$ \\
\hline & MO - 1180 & 94,3 & 5,5 & 0,1 & 0,1 & $<0,1$ \\
\hline
\end{tabular}

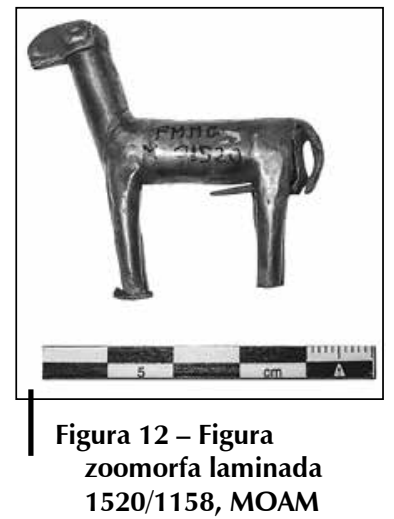

(c) L. Vetter \& M. F. Guerra

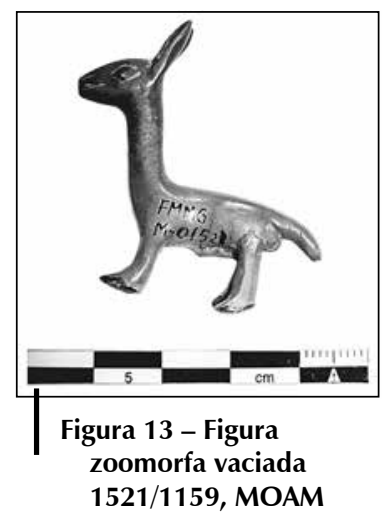

(C) L. Vetter \& M. F. Guerra

colección Larrea del Museo de América de Madrid, analizada por Rovira Llórens \& Gómez Ramos (1995), procedente del distrito de San Jerónimo en Cusco (los otros objetos analizados por los autores no tienen indicación de lugar de procedencia). La mayoría de las figuras capacocha forman un grupo distinto, caracterizado por una cantidad de plata que llega a más de 98\%, mientras que las otras se encuentran con la mayoría de los tupus. Aquellos de la región de Cusco, sean los 


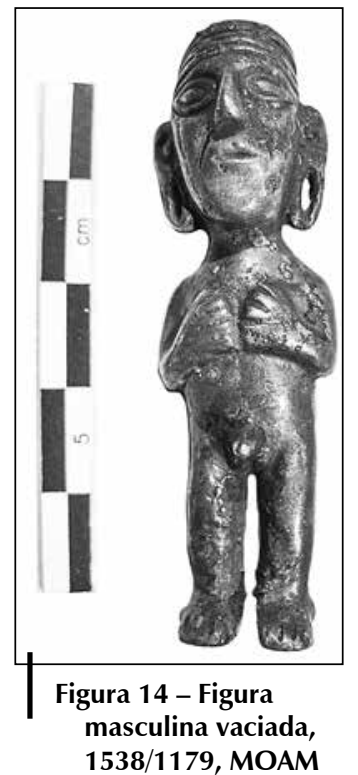

(C) L. Vetter \& M. F. Guerra

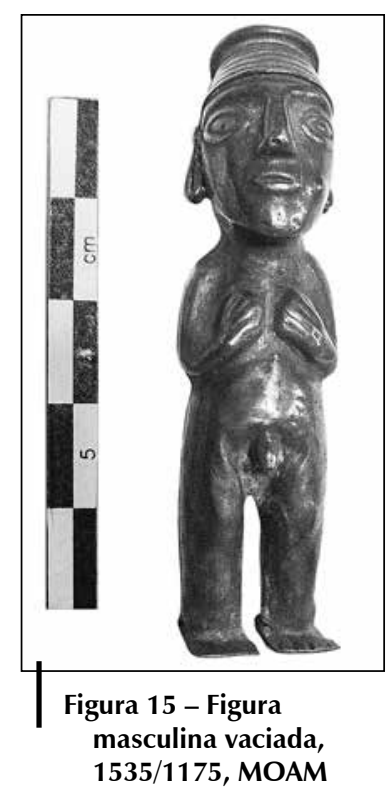

(C) L. Vetter \& M. F. Guerra

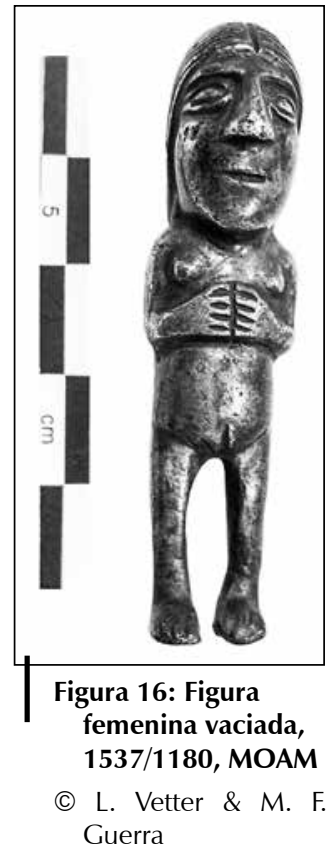

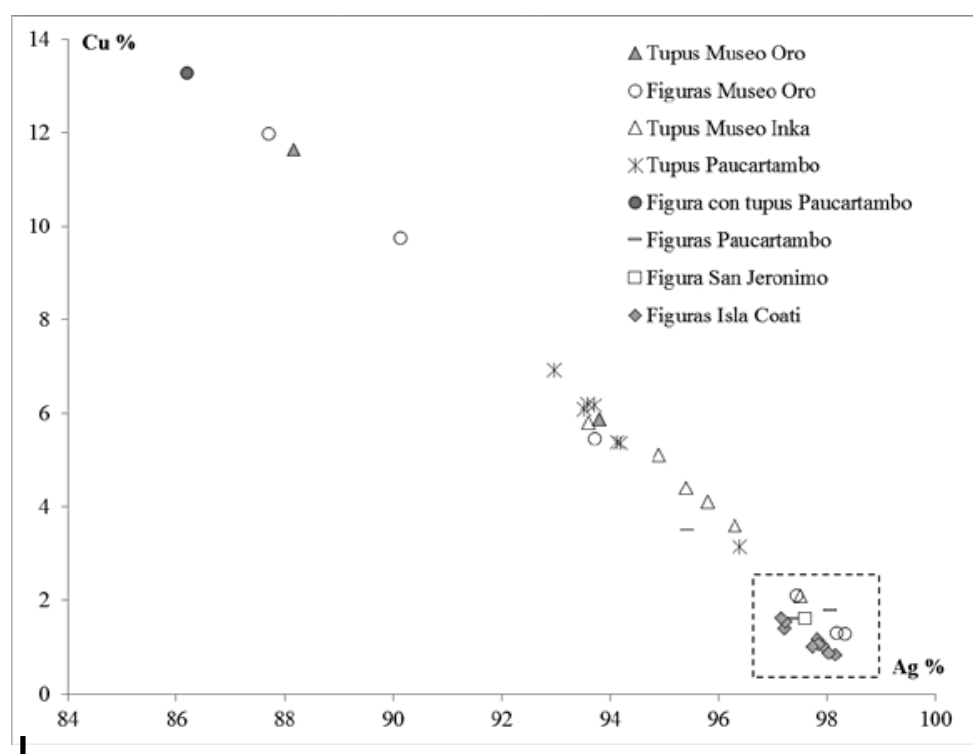

Figura 17 - Concentraciones de cobre ( $\mathrm{Cu}$ en \%) y de plata ( $\mathrm{Ag}$ en \%) determinadas en los tupus y figuras miniatura del MOAM y del MI analizados en este trabajo por FRX. Se adjuntaron las cuatro figuras de la isla Coati analizadas por Guerra et al. (en este mismo volumen), la figura de San Jerónimo (Cusco) analizada por Rovira Llórens \& Gómez Ramos (1995) todas incluidas en el cuadrado y los tupus y estatuillas de Paucartambo analizados por Sierra Palomino \& Guerra (en este mismo volumen) 
de Paucartambo o los analizados en este trabajo, se concentran en un área del gráfico que corresponde a concentraciones de cobre entre 3\% y $7 \%$. Los objetos del MOAM no tienen contexto arqueológico conocido, pero uno de los tupus se encuentra incluido en este grupo.

El grupo constituido por los objetos de mejor calidad contiene las estatuillas laminadas de la Isla de la Luna, de San Jerónimo, de Paucartambo y del MOAM. En este mismo grupo se encuentra una de las estatuillas vaciadas de Paucartambo y una de las estatuillas vaciadas del MOAM. Tomando en consideración el número de estatuillas, así como la estatuillas bicolor de Paucartambo que se encuentra en este grupo, se podría conjeturar que las estatuillas laminadas son elaboradas en Cusco $^{3}$ con una aleación distinta de la de las estatuillas vaciadas, o se trataría de producciones diferenciadas en el tiempo. Así, la composición de la estatuilla vaciada de muy buena calidad sería más una «casualidad» que una tradición de trabajo, o quizás su elaboración es más antigua.

Es notorio que tanto en la estatuilla laminada F28917 del Museo de Etnología de Berlín, publicada por Guerra et al. (en este mismo número), como en la estatuilla bicolor de Paucartambo, el peinado resulta ser poco tradicional, lo que plantearía la hipótesis de una elaboración más reciente en el caso de estas dos estatuillas, las que tenían una aleación que contiene cerca de 99\% de plata. El peinado de la estatuilla bicolor de Paucartambo es discutida en Sierra Palomino \& Guerra (en este mismo número), pero en la figura 18 se puede apreciar que una de las estatuillas femeninas capacochas del MOAM, a pesar de tener tipología y dimensiones tradicionales, posee también un peinado poco tradicional. El análisis de su composición mostró que se trata de un latón, aleación típica de la época colonial4. Este hecho parece corroborar la suposición acerca de la importancia de ciertos elementos iconográficos y metalúrgicos para el establecimiento de un terminus post quem de los objetos.

Efectivamente, las figuras miniatura vaciadas se encuentran con los tupus o son elaboradas con aleaciones con valores de cobre muy elevados. Se observa que la estatuilla de la ofrenda intacta de Paucartambo que, como ha sido indicado por Sierra Palomino \& Guerra (en este mismo número), se destacaba de las otras producciones de Paucartambo por su gran cantidad de cobre, continúa destacándose en nuestro gráfico de la figura 17. Además de un tupu del MOAM (que contiene casi $12 \%$ de cobre), solamente una de las estatuillas zoomorfas vaciadas del MOAM, la de tipología un poco distinta de la tradicional (fig. 13), con una aleación con cerca de $10 \%$ de cobre, se aproxima a la de Paucartambo. También una estatuilla zoomorfa vaciada de la colección Larrea del Museo de

3 La estatuilla masculina en plata vaciada del ajuar del niño del cerro Aconcagua en Argentina fue elaborada con una aleación con 2,7\% de cobre (Bárcena, 2004), lo que la colocaría en el grupo de estatuillas laminadas.

4 La composición de la estatuilla es la siguiente: 43\% Cu, 43\% Zn, 1\% Fe, 11\% Ni. La presencia de fuertes cantidades de Ni parece evidenciar la utilización de cuproníquel, aleación blanca empleada en la producción de monedas y ornamentos de bajo valor que se encuentra en la platería de Argentina y Chile del siglo XIX (Guerra \& Núñez-Regueiro, 2012; Núñez-Regueiro \& Guerra, 2016). 
América de Madrid, analizada por Rovira Llórens \& Gómez Ramos (1995), sin indicación de lugar de procedencia y de tipología muy poco tradicional, contiene casi $13 \%$ de cobre $^{5}$. Pero las estatuillas vaciadas pueden contener grandes cantidades de cobre, como se puede apreciar en la figura 19. Una estatuilla masculina sin proveniencia del MOAM, cuya composición se encuentra en el cuadro 4 , contiene $24 \%$ de cobre.

Volviendo al grupo de las estatuillas laminadas de la figura 17 , se puede ver que uno de los tupus del $\mathrm{MI}$ analizados en este trabajo se encuentra también en ese grupo. Todos los otros tupus se encuentran entre este grupo y los tupus miniatura de Paucartambo analizados por Sierra Palomino \& Guerra (en este volumen). Al

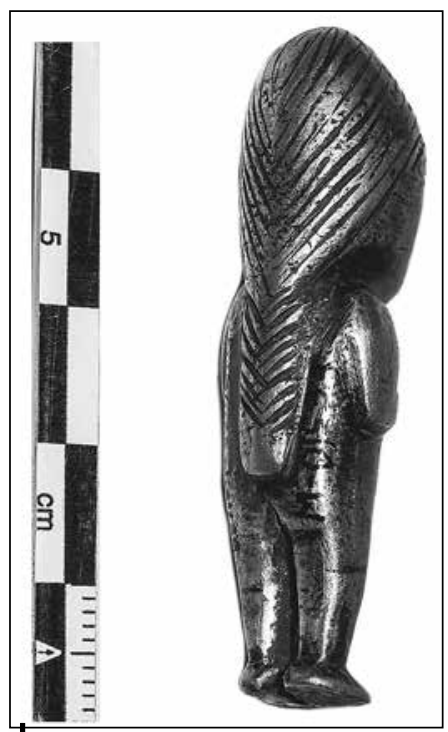

Figura 18 - Figura femenina vaciada del MOAM: 1178

(C) L. Vetter \& M. F. Guerra

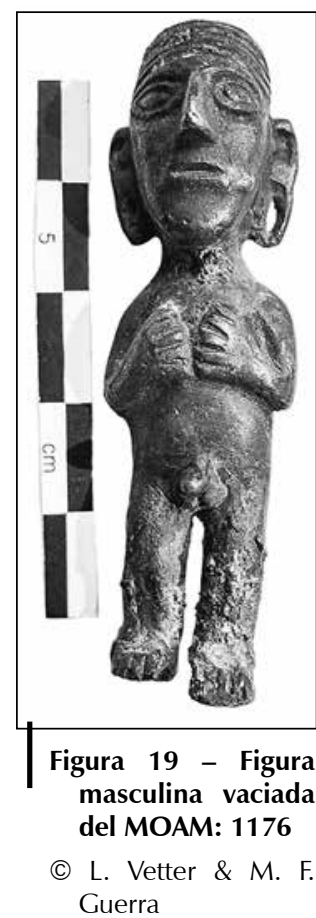

Cuadro 4 - Composición, normalizada al 100\%, de las estatuillas vaciadas 1176 y 1178 del MOAM (FRX)

\begin{tabular}{|cccccccc|}
\hline Referencia & Au \% & Ag \% & Cu \% & Zn \% & Fe \% & Ni \% & Pb \% \\
mo1176 & 0,3 & 72,8 & 26,5 & & & & 0,4 \\
& & & & & & & \\
mo1178 & & & 45,2 & 43,4 & 0,8 & 10,6 & \\
\hline
\end{tabular}


contrario de lo fue propuesto por dichos autores a partir de los análisis de los objetos de Paucartambo, el tupu miniatura que contiene cerca de $3 \%$ de cobre no es distinto, pues se encuentra en nuestro gráfico en un área ligeramente mayor, con composiciones que parecen corresponder a las aleaciones de «los tupus de Cusco». Uno de los tupus del MOAM se encuentra también con esos tupus, pero no es posible hacer alguna deducción pues no tiene procedencia conocida.

Consideramos en la figura 20 los cuatro tupus de tipología idéntica a los nuestros, de la colección Larrea del Museo de América de Madrid, analizados por Rovira Llórens \& Gómez Ramos (1995), el único tupu de plata del valle del Mantaro analizado por Howe \& Peterson (1994), y el único analizado por Gordon \& Knopf (2007) de los ocho tupus de plata excavados por Hiram Bingham en Machu Picchu, durante su expedición al Perú en 1912 (Yale). Sin embargo, la variabilidad encontrada para las aleaciones es esperada, pues como se dice líneas arriba, se manufacturaron tupus en plata, en bronce estañífero y otros bronces. Muchos de los tupus considerados no están fechados y carecen de contextos conocidos, pero los tres tupus del Museo de América se encuentran con los de Cusco.

De los resultados obtenidos para los tupus de plata de la región de Cusco se puede suponer y especular lo siguiente (pues no hay resultados concretos que permitan afirmarlo): 1) las aleaciones de plata para la elaboración de los

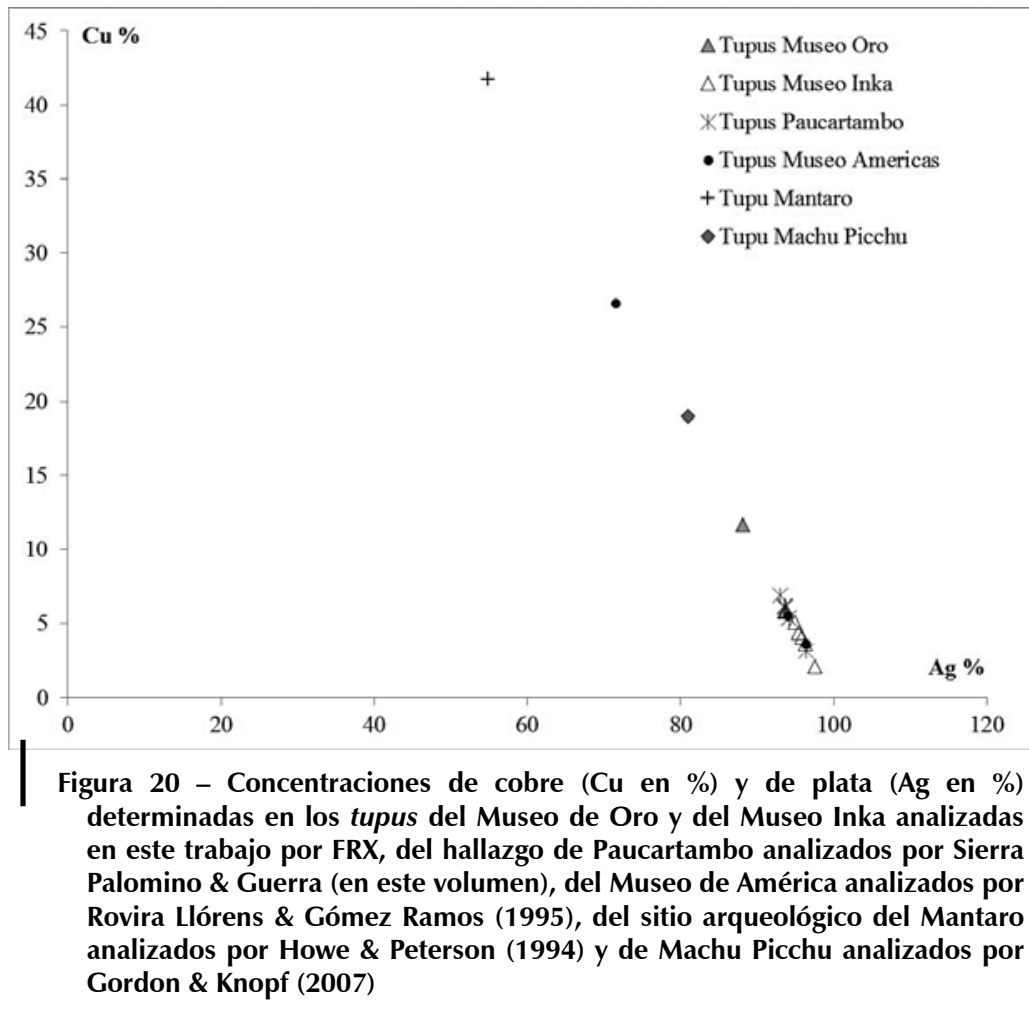


tupus eran distintas de las aleaciones de plata para la elaboración de las figuras miniatura; 2) las aleaciones de plata para la elaboración de las figuras laminadas eran distintas y de muy buena calidad (al igual que la de una figura vaciada, pero solo una, es también de buena calidad); 3) para elaborar los tupus se recurriría a un procedimiento metalúrgico basado en aleaciones de plata con contenidos de cobre bien definidos, que variarían ligeramente con la época de producción, pero se encontrarían normalmente entre $2 \%$ y $7 \%$; 4) el grupo de tupus de Paucartambo fue elaborado en el mismo periodo, pero es posible que el tupu que se diferencia pertenezca a otra época.

Para verificar esas hipótesis será necesario incrementar la cantidad de tupus analizados, e incluir en el estudio otros objetos de plata de los mismos contextos arqueológicos. Varios de los tupus custodiados en el Museo Inka provienen de contextos funerarios, aunque hay otros tupus que no han sido hallados en un contexto claro. Los tupus 13 y 14 fueron encontrados en un contexto funerario en Ollantaytambo, en el sitio de Patacancha. Estos tupus se encontraban asociados a una gran cantidad de objetos de metal y concha. Como parte de los objetos de metal se encuentran otros doce tupus, tres aquillas, un brazalete, una figura masculina, tres llamas masculinas, cuentas de concha y una llama del mismo material. El tupu 15 procede de Sacsaywaman y fue hallado en un contexto funerario acompañado de otros cinco tupus y de una aguja de metal, además de gran cantidad de cerámica y restos óseos humanos y de animal. Los tres tupus restantes no tienen contexto conocido. El tupu 17 procede de Quillabamba y se asocia con otro tupu. De Pachar-Anta proviene el tupu 18, y se le asocia con dos tupus más y una llama. Por último, el tupu 21 procede de Walla Walla y se asocia a otro tupu, una figura femenina, otra masculina y una llama masculina. El Catálogo Razonado del Museo de Arqueología, Departamento de Arte Incaico, de la UNSAAC (1936), de donde hemos obtenido esta información, indica que todos estos hallazgos son de la «Cultura Inca».

Sin embargo, esta última afirmación no implica necesariamente que estas piezas fueron manufacturadas en el periodo inca. Es probable que estas piezas puedan haber sido manufacturadas luego de la conquista europea por manos indígenas, pero con metales cuya composición en plata sea distinta a la época anterior debido al lugar de procedencia de los mismos o al tipo de aleación que se empleó. Estos objetos, como los tupus y las estatuillas, continuaron fabricándose después de la conquista europea por los plateros indios, y siguieron siendo enterrados como ofrendas, tal como se lee en la siguiente cita:

Yten[sic] por quanto en esta ciudad y sus términos, assi en poder de españoles, como fuera del, ay muchos yndios plateros que entienden en el oficio de labrar plata de que resultan muchos inconbenientes, assi de mesclarla con otros metales, y abajarla de la ley, como porque los quintos de la dicha plata labrada no bienen a la fundición real en mucho tiempo y es fraude que se hase en la dicha cobranza de los dichos quintos demás de lo qual los dichos yndios plateros labran basos, y otras cosas para sí de que se defrauda el quinto para siempre porque se entierran con los dichos 
basos, e los meten debaxo de tierra en otras partes por diferentes opiniones que tienen, y labran en ellos figuras, e ydolos cada uno según su propósito todo perjudicial, y pernicioso6.

\section{PLATA MONETARIA Y PRODUCCIONES INCAICAS}

La explotación inca de los yacimientos mineros bolivianos en Potosí y Porco (Van Buren \& Presta, 2010) antes de la llegada de los españoles aparece documentada (Bouysse-Cassagne, 2005; 2008). De hecho, según Platt \& Quisbert:

tanto los Inkas como los Mallcos de Qaraqara estaban perfectamente conscientes del tesoro que encerraba el Cerro Rico (Platt \& Quisbert, 2010: 233).

La situación geográfica de las minas de plata de Potosí, cerca de la capital del imperio inca, plantea la posibilidad de su uso en la producción de objetos incas.

El descubrimiento por los españoles en 1545 de las minas de Potosí y otras minas de plata como Porco y Charcas (Platt et al., 2006) concentradas en la cordillera de Los Frailes de Potosí (Cruz, 2009), transformó la economía mundial. En 1570-1572, Pedro Fernández de Velasco introdujo el procedimiento minero de tratamiento por amalgama de mercurio de los minerales de plata de los ricos yacimientos bolivianos (Vetter, 2008), lo que permitió su explotación intensiva y una producción masiva de este metal precioso. A partir de este se produjo una de las monedas más representativas de la economía mundial: el real de a ocho (o peso fuerte), que se inspira en el Thaler alemán, y que forma con la onza el sistema monetario de la monarquía española desde la reforma de 1497 hecha por los Reyes Católicos. Esta moneda, con una ley de 93,1\% de plata, acuñada no solamente en la ceca de Potosí, sino también en otras cecas de América del Sur y de España, se convierte en el siglo XVI en referente para el comercio mundial, sirviendo durante varios siglos como divisa internacional (Trapero, 2005).

La geoquímica específica de los yacimientos de los Andes bolivianos, como el Cerro Rico de Potosí, permite caracterizar químicamente la plata suramericana y diferenciarla de la plata utilizada en España a principios del siglo XVI, por un simple análisis químico de las cantidades de oro e indio presentes en las aleaciones de las monedas de plata (Guerra, 1990; 2000). Fue también posible datar la difusión de la plata boliviana en Europa y su sustitución por la plata de los ricos yacimientos de México, cuyo inicio de explotación es casi simultáneo al de las minas bolivianas (Guerra, 2004).

Por ahora no es posible analizar tupus con técnicas analíticas que proporcionen los elementos trazas característicos de los yacimientos bolivianos, pues sería necesario tomar una muestra o trasladar el objeto del museo al laboratorio. Sin embargo, se puede especular sobre el uso de aleaciones típicas de los reales de a ocho, para su producción en la época colonial7.

6 ABNB ALP, EC 1764/131, f. 68. "Ordenanza del Virrey don Francisco de Toledo prohibiendo la hechura de akillas de oro y plata con objetos de idolatría (20 de diciembre de 1574)".

7 El empleo de moneda para la elaboración de platería es conocido en los Andes, en particular por el pueblo mapuche (Guerra \& Núñez-Regueiro, 2012; Núñez-Regueiro \& Guerra 2016). 
En la figura 21 se muestran las concentraciones de los dos elementos mayoritarios (cobre y plata) en las monedas acuñadas en la ceca de Potosí (Guerra, 1990; 2000) y las composiciones de los tupus y estatuillas.

La gran mayoría de estatuillas y tupus estudiados se encuentra fuera del grupo de monedas acuñadas en Potosí. Los resultados indican que no hay, en general, uso directo de aleaciones de tipo monetario para fabricar estos objetos. Las ceremonias incaicas y los intereses de la Corona aparecen así bien alejados.

Se puede todavía reflexionar sobre los tupus miniatura de Paucartambo, pues sus aleaciones muy regulares corresponden a las de las monedas acuñadas en Potosí. Del mismo modo, los tupus que pertenecen a la figura de la ofrenda intacta de Paucartambo están en este grupo, lo que confirma la regularidad del trabajo del platero. ¿Se trata de una realidad o de una casualidad? La aleación de esta figura se destaca del grupo y podría corresponder a una elaboración más reciente. Pero con los datos analíticos de los cuales disponemos hoy no es posible saberlo. Solo el análisis con técnicas físico-químicas más sofisticadas podrá indicar de dónde proviene la plata, lo que abriría otras posibilidades de atribución.

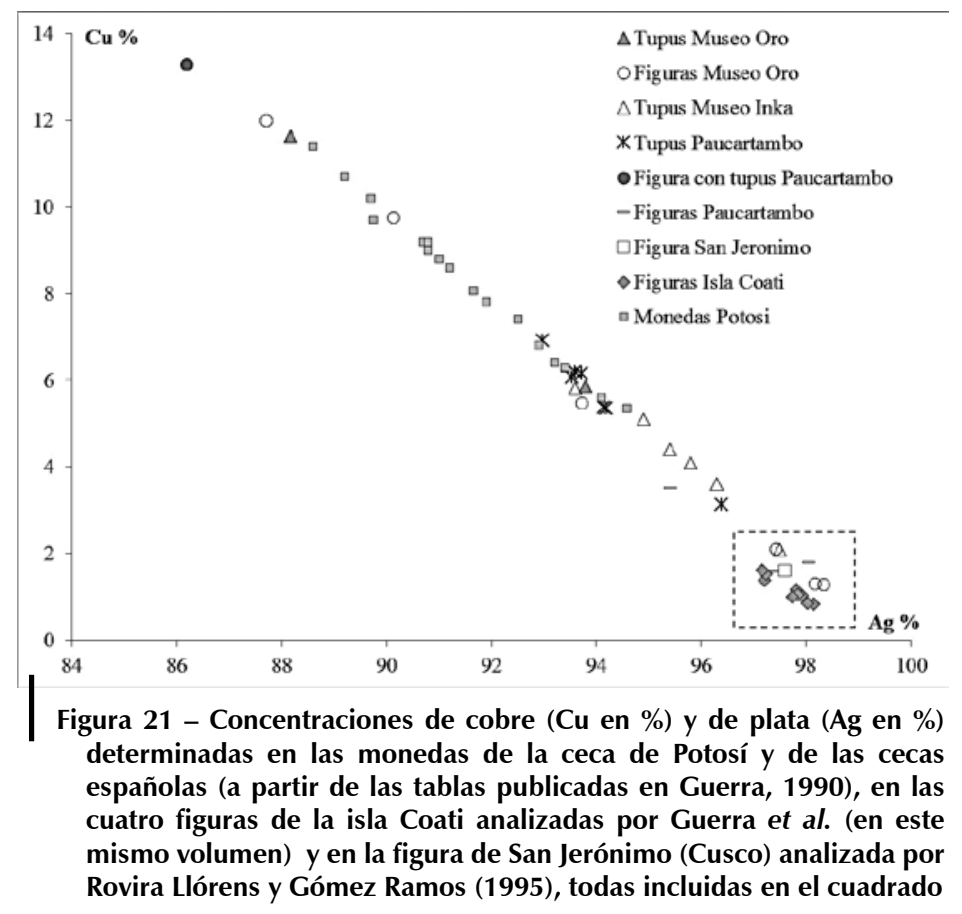

\section{CONCLUSIÓN}

De acuerdo a la información disponible, no hay publicaciones sobre análisis de los productos provenientes de los centros de fundición, ni de la cadena de producción 
orfebre en Cusco, ni del procesamiento final de la plata, que posiblemente era hecho solo en Cusco (por ejemplo Zori \& Tropper, 2010).

Hay evidencia arqueológica de que la fabricación de piezas de metal en la región andina durante el periodo prehispánico se realizaba en talleres, a manos de un amplio y variado grupo de expertos orfebres, quienes se ubicaban en las ciudades o en las plataformas de los centros ceremoniales. Ejemplos arqueológicos de esta actividad orfebre se encuentran en las investigaciones en Tambo de Mora, Chincha, donde se ha encontrado una importante zona de hornos para el trabajo de orfebrería en un periodo transicional entre las culturas Chincha e Inca, lo que indica una especialización del trabajo orfebre desde la época chincha en esta región (Alcalde et al., 2002). Algunos cronistas nos ilustran sobre los talleres de orfebrería para la época inca, los cuales, como veremos, no se encontraban solo en Cusco. Benzoni es uno de los cronistas del siglo XVI que comenta sobre el trabajo orfebre y el lugar dónde se hallaban los talleres:

Esa Provincia de Quito es de aire templado, por lo cual los Reyes del Cusco vivían allí la mayor parte del tiempo, manteniendo en muchos sitios casas de orfebres, los que sin conocer el uso de ningún instrumento de fierro, toscamente labrando hacían cosas maravillosas [sic] (Benzoni, 2000 [1572]: 118).

Otro cronista es Cieza de León quien describe, por ejemplo, el caso de Jauja en la época incaica:

En todas estas partes auían grandes aposentos de los Ingas: aunque los más principales estauan en el principio del valle en la parte que llaman Xauxa[...]. Sin lo qual auía grande número de plateros, que labrauan vasos y vasijas de plata y de oro para el servicio de los Ingas y ornamentos del templo (Cieza de León, 1996 [1553]: cap. Ixxxiii, 242).

En otra parte del texto, añade lo siguiente:

Pues la chaquira tan menuda y pareja la hacen, por lo qual paresce auer grandes plateros en este reyno. Y ay muchos de los que estauan puestos por los reyes Ingas en las partes más principales dél (Cieza de León, 1996 [1553]: cap. cxiiii, 300).

Es así difícil avanzar con hipótesis concretas sobre la elaboración de tupus y estatuillas con los resultados obtenidos para un conjunto en el que incluimos los datos de otros autores para aumentar la muestra utilizada, aunque esta resulta aún demasiado pequeña para la complejidad del tema abordado.

No obstante, resulta evidente que, en general, las estatuillas laminadas de la región de Cusco son hechas con aleaciones de plata de muy buena calidad. Solo una estatuilla vaciada fue elaborada con una aleación de buena calidad, como las laminadas. Algunas de las estatuillas vaciadas, como aquella de la ofrenda intacta de Paucartambo, podrían tratarse de producciones cercanas al periodo de contacto. El peinado y el tipo de la estatuilla bicolor de este mismo hallazgo tendrían que corroborar esta afirmación.

La tecnología de elaboración de los tupus, comparada con el vaciado y el laminado de las estatuillas, no justifica la utilización de aleaciones distintas. Sin embargo, los 
tupus de la región de Cusco fueron fabricados con aleaciones idénticas, como si el procedimiento metalúrgico fuera muy regular y controlado. El grupo de tupus miniatura del hallazgo de Paucartambo es muy homogéneo, su composición está tan parecida a las aleaciones monetarias coloniales de la ceca de Potosí que es tentador imaginar que se trata de una producción de esta época o de cuando el platero indio se integraba a un grupo que producía regularmente estos objetos. La información dada en el Catálogo del Museo Inka indica solamente que estas piezas pertenecen a la «Cultura Inca», lo que no implica necesariamente que fueron manufacturadas en el periodo de ocupación inca; podrían haber sido manufacturadas luego de la conquista europea por manos indígenas.

Pero la regularidad u homogeneidad del conjunto podría también ser justificada a través de la utilización de un procedimiento metalúrgico a pequeña escala del periodo de ocupación inca o posterior. Las composiciones obtenidas por Zori \& Tropper (2010) para las pepitas de plata procedentes de la purificación en pequeña escala de este metal en el sitio inca y colonial de Tarapacá Viejo (Chile), muestran que las cantidades de cobre presentes en la aleación son exactamente las mismas que aquellas de los tupus de la región de Cusco. Estas aleaciones de plata que llegarían a los talleres plateros de Cusco, podrían ser utilizadas directamente para elaborar los tupus sin pasar por otros procedimientos de refinación conocidos de los plateros, pero dispendiosos, inaccesibles o innecesarios. Es interesante señalar que estos tupus miniatura contienen valores más elevados de plomo.

Es posible especular sobre los resultados obtenidos. Las estatuillas que, al contrario de los tupus, eran solamente consagradas a ritos y ofrendas, beneficiarían entonces eventualmente a una producción menos regular y controlada por otros orfebres u orfebres «especializados» (i?), cuya destreza les permitiría repujar, cincelar, etc. El conocimiento de estas técnicas no es necesario para elaborar tupus.

Se podría también suponer la existencia de orfebres con destrezas específicas, diferenciando los que vaciaban de los que laminaban. Era por ejemplo el caso en Pampa Grande, en la región Lambayeque, donde Shimada identificó para la fase estilística Moche $V$, cuatro áreas bien definidas: el área para el recocido y vaciado del metal, el área para cortar y formar láminas de metal, el área de almacenamiento y consumo de bebida y comida, y el área de preparación de alimentos (Shimada, 1994: 203), distinción que una vez más no se aplicaría a quien elaboraría los tupus y que explicaría las aleaciones encontradas.

Queda así la perspectiva de analizar más tupus y estatuillas en plata de la región de Cusco, en particular los contextualizados, y otros objetos de estos mismos hallazgos elaborados en el mismo metal, para intentar comprender el procedimiento de los talleres. En cuanto a la procedencia de la plata que aprovisiona estos talleres, solamente resultados analíticos obtenidos por otras técnicas permitirán diferenciar las diversas fuentes de plata andina. 


\section{Agradecimientos}

Las autoras agradecen a Victoria Mujica y Patricia Arana, Directora y curadora del Museo de Oro y Armas del Mundo de Lima; y a Edith Mercado, Directora del Museo Inka de la Universidad Nacional de San Antonio Abad del Cusco, por permitirles estudiar las piezas que se custodian en estos museos. Asimismo, agradecen a Marco Zamalloa Jara de la UNSAAC y Juan Aponte de Symtek - Perú por realizar los análisis por FRX.

\section{Referencias citadas}

\section{Fuente primaria}

ARCHIVO Y BIBLIOTECA NACIONAL DE BOLIVIA

Ordenanza del Virrey don Francisco de Toledo prohibiendo la hechura de akillas de oro y plata con objetos de idolatría. (20 de diciembre de 1574)

Signatura: Expedientes Coloniales, BO ABNB ALP, EC 1764/131, f. 68.

ALCALDE, J., DEL ÁGUILA, C., FUJITA, F. \& RETAMOZO, E., 2002 - 'Plateros' precolombinos tardíos en Tambo de Mora, Valle de Chincha (Siglos XIV y XVI). Anales del Museo de América, 10: 43-57; Madrid.

BENZONI, G., 2000 [1572] - La Historia del Mondo Nuovo (Relatos de su viaje por el Ecuador, 1547-1550), 135 pp.; Guayaquil: Museo Antropológico, Pinacoteca del Banco Central del Ecuador. Traducción, introducción y notas de Carlos Radicati Di Primeglio.

BÁRCENA, J. R., 2004 - Las piezas metálicas de la ofrenda ritual del Cerro Aconcagua. Mendoza, República Argentina. Anejos de Anejos de Archivo Español de ArqueologíaAESPA, XXXII: 157-172.

BOUYSSE-CASSAGNE, T., 2005 - Las minas del centro-sur andino, los cultos prehispánicos y los cultos cristianos. Bulletin de l'Institut Français d'Études Andines, 34 (3): 443-462.

BOUYSSE-CASSAGNE, T., 2008 - Minas del sol, del Inka y de la gente. Potosí en el contexto de la minería prehispánica. In: Mina y metalurgia en los Andes del Sur desde la época prehispánica hasta el siglo XVII (P. Cruz \& J.-J. Vacher, eds.): 303-348; Lima: IFEA, IRD.

CATÁLOGO RAZONADO DEL MUSEO DE ARQUEOLOGÍA, DEPARTAMENTO DE ARTE INCAICO, UNIVERSIDAD DEL CUZCO, 1936.

CIEZA DE LEÓN, P., 1996 [1553] - Crónica del Perú. Primera Parte, 352 pp.; Lima: Pontificia Universidad Católica del Perú, Fondo Editorial y Academia Nacional de la Historia.

CRUZ, P., 2009 - Huacas olvidadas y cerros santos. Apuntes metodológicos sobre la cartografía sagrada en los Andes del sur de Bolivia. Estudios Atacameños, 38: 55-74.

GORDON, R. \& KNOPF, R., 2007 - Late horizon silver, copper and tin from Machu Picchu, Peru. Journal of Archaeological Science, 34: 38-47.

GUERRA, M. F., 1990 - A caracterização dos arqueometais. Análise quantitativa por métodos nucleares e perinucleares, 425 pp.; Lisboa: Tesis de Doctorado en Física Aplicada, Universidade Nova de Lisboa, Portugal.

GUERRA, M. F., 2000 - The mines of Potosi: A silver El Dorado for the European economy. In: Ion Beam Study of Art and Archaeological Objects (G. Demortier \& A. 
Los tupus y estatuillas de plata inka: una aproximación a sus aleaciones

Adriaens, eds.): 88-94; Luxemburgo: Directorate-General for Research, European Communities.

GUERRA, M. F., 2004 - The circulation of South American precious metals in Brazil in the end of the 17th century. Journal of Archaeological Sciences, 31 (1): 225-1236.

GUERRA, M. F., 2008 - An overview on the ancient goldsmith's skill and the circulation of gold in the past: the role of X-ray based techniques. X-ray Spectrometry, 37-4: 317-327.

GUERRA, M. F. \& NÚÑEZ-REGUEIRO, P., 2012 - Indigenous silver jewellery of Northern Patagonia (19th century): Analytical approach to composite objects. X-Ray Spectrometry, 41: 342-349.

HOWE, E. G. \& PETERSON, U., 1994 - Silver and lead in the Late Prehistory of the Mantaro Valley, Peru. In: Archaeometry of Pre-Columbian Sites and Artifacts (D. A. Scott \& P. Meyers, eds.): 183-197; Los Angeles: The Getty Conservation Institute.

NÚÑ̃EZ-REGUEIRO, P. \& GUERRA, M. F., 2016 - Los aros de plata de Patagonia septentrional: aportes de la colección Henry de la Vaulx (1896) sobre forma, tecnología y metalurgia. Chungara, Revista de Antropología Chilena, en prensa.

PLATT, T. \& QUISBERT, P., 2010 - Tras las huella del silencio: Potosí, los incas y Toledo. Runa, 31 (2): 115-152.

PLATT, T., BOUYSSE-CASSAGNE, T. \& HARRIS, O., 2006 - Qaraqara-Charka. Mallku, Inka y Rey en la provincia de Charcas (siglos XV-XVII). Historia antropológica de una confederación ayamara, 1088 pp.; Lima: Plural editores, IFEA, University of St. Andrews, University of London, Interamerican foundation, Fundación cultural del Banco Central de Bolivia.

RICHET, D., LE ROY LADURIE, E., GORDUS, A. \& GORDUS, J., 1972 - Le Potosi et la physique nucléaire. Annales. Économies, Sociétés, Civilisations, 27 (6): 1235-1256.

ROVIRA LLORÉNS, S. \& GÓMEZ RAMOS, P., 1995 - Los objetos de metal de la Colección Juan Larrea: un estudio arqueometalúrgico. Anales del Museo de América, 3: 21-33.

SHIMADA, I., 1994 - Pampa Grande and the Mochica Culture xv + 323 pp.; Austin: University of Texas Press.

TRAPERO, M. R., 2005 - El real de a ocho: su importancia y trascendencia. In: IV Jornadas Científicas Sobre Documentación de Castilla e Indias en el siglo XVI (S. C. Fontanilla \& M. M. R. Martínez, eds.): 357-378; Madrid: Dpto. de Ciencias y Técnicas Historiográficas, Universidad Complutense de Madrid.

TROALEN, L. \& GUERRA, M. F., 2016 - Gold from the tomb of Scribe Beri: a comparative analytical approach to the New Kingdom gold grave goods from Riqqa (Egypt). Applied Physics A, 122 (3): 209-220.

VAN BUREN, M. \& PRESTA, A. M., 2010 - The organization of Inka silver production in Porco, Bolivia. In: Distant provinces in the Inka empire: Toward a deeper understanding of Inka imperialism (M. A. Malpass \& S. Alconini Mujica, eds.): 173192; lowa City: University of lowa Press.

VETTER, L. 2007 - La evolución del tupu en forma y manufactura desde los Incas hasta el Siglo XIX. In: Metalurgia en la América Antigua. Teoría, arqueología y tecnología de los metales prehispánicos (R. Lleras, ed.): 101-128; Bogotá: Fundación de Investigaciones Arqueológicas Nacionales, Banco de la República de Colombia, IFEA. 51 Congreso Internacional de Americanistas, Santiago de Chile, Chile, julio, 2003. Simposio: Metalurgia en la América Antigua.

VETTER, L., 2008 - Plateros indígenas en el Virreinato del Perú: siglos XVI y XVII, 292 pp.; Lima: Universidad Nacional Mayor de San Marcos-Fondo Editorial. 
VETTER, L., 2009 - El uso del tupu en un pueblo llamado Tupe. In: Platería Tradicional del Perú. Usos domésticos, festivos y rituales: siglos XVIII-XX: 175-183; Lima: Universidad Ricardo Palma, Instituto Cultural Peruano Norteamericano.

VETTER, L., 2013 - El platero indio en los Andes: siglos XVI y XVII; Lima: Pontificia Universidad Católica del Perú. Tesis para optar el grado académico de Doctora en Historia con mención en Estudios Andinos.

VETTER, L., 2016 - Plateros y saberes andinos: el arte orfebre en los siglos XVI y XVII, 326 pp.; Lima: Centro Bartolomé de las Casas, Academia Nacional de Ciencias.

VETTER, L. \& CARCEDO, P., 2009 - El tupo: Símbolo ancestral de identidad femenina, 128 pp.; Lima: Gráfica Biblos.

VETTER, L., PETRICK., S., HUAYPAR, Y. \& MAC KAY, M., 2008 - Los hornos metalúrgicos del sitio Inca de Curamba (Perú): Estudio por DRX, espectroscopia Mössbauer y datación por métodos de luminiscencia. Bulletin de l'Institut Français d'Études Andines, 37 (3): 451-475; Lima. 52 Congreso Internacional de Americanistas, Sevilla. Julio, 2006.

ZORI, C. M. \& TROPPER, P., 2010 - Late pre-Hispanic and early Colonial silver production in the Quebrada de Tarapacá, Northern Chile. Boletín del Museo Chileno de Arte Precolombino, 15: 65-87. 